\title{
Rencontre à propos de mises en scène de Bernard Sobel du Juif de Malte et d'Édouard II
}

\section{Alain Girault et Michèle Raoul-Davis}

Marie-Thérèse Jones-Davies (éd.)

\section{(2) OpenEdition}

Journals

Édition électronique

URL : http://journals.openedition.org/shakespeare/137

DOI : $10.4000 /$ shakespeare. 137

ISSN : 2271-6424

Éditeur

Société Française Shakespeare

Édition imprimée

Date de publication : 1 novembre 1980

Pagination : 153-155

Référence électronique

Alain Girault et Michèle Raoul-Davis, "Rencontre à propos de mises en scène de Bernard Sobel du Juif de Malte et d'Édouard II », Actes des congrès de la Société française Shakespeare [En ligne], 2 | 1980, mis en ligne le 01 novembre 2007, consulté le 22 avril 2019. URL : http://journals.openedition.org/ shakespeare/137; DOI : 10.4000/shakespeare.137 


\section{SOCIÉTÉ FRANC̣AISE SHAKESPEARE}

\section{ACTES DU CONGRĖS 1980}

DIRECTEUR DE LA PUBLICATION

M.T. Jones - Davies

JEAN TOUZOT Libraire - Editeur 38 , rue Saint-Sulpice 75278 PARIS CEDEX 061981 


\section{JEUDI 13 NOVEMBRE}

Rencontre avec Alain Girault et Michèle Raoul-Davis à propos de deux mises en scène de Bernard Sobel : Le Juif de Malte (janvier 1976) et Edouard // (prévu pour janvier 1981).

LE JUIF DE MALTE, où l'opposition des formes, les ruptures, les incertutudes du texte créent les conditions d'une «ironie baroque» ( $R$. Barthes), a permis au Théâtre de Genevilliers un travail sur les codes dramaturgiques mis en jeu.

Le schéma de moralité - Par une ruse de dramaturge, Marlowe introduit à l'intérieur d'une «moralité», plusieurs «machiavels». L'ironie dramaturgique est mise en évidence par la victoire sur les autres du plus machiavélien de ces machiavels : Ferneze. La moralité se plie aux exigences du machiavélisme.

L'éclatement de l'intrigue - Le bouleversement, la dispersion de l'intrigue font que plusieurs branches dramatiques se répondent, jouent l'une par rapport à l'autre, se démystifiant mutuellement. L'intrigue centrale est coiffée par une intrigue supérieure où se déroulent les conflits historiques, politiques, philosophiques et elle se reflète en contrepoint dans une intrigue inférieure, clownesque, carnavalesque, où se parodient les effets tragiques. Cette construction horizontale sert d'appui à un découpage vertical -trois moralités successives où se refait, à chaque fois, le trajet qui mène du péché absolu à un enfer de carton-pâte, donc deux cassures : V, I et surtout fin I - début II, où Barabas refuse de donner son argent pour raison de judéité.

L'allégorie du Juif - Barabas n'est pas juif naturellement. Il est celui que les autres désignent comme juif (Sartre). Face à Ferneze, aux «autres» dont l'attitude repose sur des raisons religieuses, économiques, politiques, Barabas se met en condition d'être le juif, il est conduit à «théâtraliser»sa situation de juif désigné comme tel. D'où l'idée de l'affubler d'un faux nez, signe de son «rôle» de juif. Jusqu'à la cassure, nous avons donc un juif à visage découvert. Pendant le monologue de Barabas se produit la «prise du nez», le revêtement de l'emblème de judéité. L'entrée d'Abigail correspond à cet endossement du rôle du juif. Barabas, juif «authentique» dans la mesure où il est 
honni et proscrit, se revendique comme tel. Abigail, juive «inauthentique», trop pure pour se défendre,est, elle,l'image de l'innocence broyée. Par un diabolisme théâtral, le protagoniste accentue la judéité que lui imposent les autres et entend s'identifier au mal absolu - pour les contemporains de Marlowe et au théâtre : Machiavel. Ce machiavélisme individuel échoue pourtant face au vrai machiavélisme d'Etat, froid et calculateur. La mort de Barabas, qui disparaît dans la trappe qu'il avait préparée pour d'autres, est le deuxième temps fort de la pièce - accentuée par la retombée du rideau de scène. Grâce à cet artifice théâtral, la mise en scène fait ressortir la dialectique qu'établit la pièce de Marlowe entre : le juif bouc-émissaire et le chrétien organisateur de son élimination, l'individualisme paranoïaque et la froide lucidité de l'Etat, le machiavel manqué et le machiavel authentique, le prince rêvé (dont Barabas est une forme parodiée) et le prince réel (qui marque le passage du monde de la féodalité à celui de la bourgeoisie montante), enfin les formes emblématiques de la moralité face aux options réalistes d'un autre théâtre, où les oppositions d'ordre métaphysique entre le Bien et le Mal cèdent le pas à des conflits réels entre les hommes. La disparition de Barabas correspond à la naissance d'une nouvelle dramaturgie. D'où la démarche du théâtre de Genevilliers : après avoir privilégié le «sens» (étape brechtienne, historiciser la fable : Timon d'Athènes) puis la «dramaturge» (étape «baroque»: découvrir le jeu des formes dramatiques et leur cohérence :Dom Juan, La tempête, Le précepteur (Lenz), L'abime (Ostrowsky), Le Juif de Malte), il considère aujourd'hui comme premier le rapport acteur-spectateur, où le sens du spectacle prend forme au cours de l'acte dramatique.

EDOUARD II , tragédie historique, met en scène une époque d'ébranlement, où tout est mis en cause, le passage d'un ordre féodal à une légitimité nouvelle où s'affermissent les bases d'une nation. Edouard II (à la différence d'un Lear) flotte dans une défroque royale trop grande pour lui. Il regarde la royauté comme un enfant l'âge adulte, il ne réussit pas à dépasser le principe du plaisir - marque personnelle de son destin. Sur le plan personnel, la course tragique se clôt par la mort du père, de même qu'elle débute par la rupture avec la loi du père. (Edouard II aura la charge, 
par-delà le cercueil du père de se réconcilier avec la nation). Le «personnage» Edouard II, en perpétuelle position de jeu, histrion tragique, joue les Tamerlan, les tyran, les anté-christ mais c'est pour mieux fuir ses responsabilités de roi. Tricheur, ridicule, atroce (sa fin) ce souverain indigne ruse avec lui-même, joue avec l'Histoire. A la différence d'un Richard II, il n'est pas l'oint du Seigneur. Confronté à son rôle historique, il demeure dérisoire. La démarche Marlovienne est dans l'exploitation de la tension entre le personnage et son rôle. La tragédie, chez Marlowe, est dans la rupture entre fonction royale et personne du roi.

Au départ d'un travail sur une mise en scène future -où les acteurs auront à établir un rapport de «jeu» avec leur personnage, où «jouer» et «parler» seront, comme chez Edouard II, une façon de ruser avec le réel - la pièce apparaît comme un espace d'expérimentation. (Le jeu sur les codes ne s'y impose pas comme dans Le Juif de Malte). Les questions sur la légitimité, les deux «corps»du roi, ses rapports avec les nobles, les communs, son peuple, se posent moins par l'intermédiaire d'une tragédie historique que sous la forme d'une tragédie de la personne du roi. La décomposition du corps royal - - souillé, coupable,objet de répulsionest la métaphore dramatique d'une décomposition du corps social - corps écartelé de la noblesse, exsangue du peuple, adultère de la reine (par la faute et la volonté du roi), usurpateur (malgré lui et par la faute du père) de son fils. Il débouche sur une mort horrible et rédemptrice, à la fois personnelle, politique et emblématique. 